\title{
Historic preservation in Aguascalientes, Mexico: urban regeneration, new corporate centralities and sustainability
}

\author{
A. Acosta Collazo \\ Departamento de Diseño del Hábitat, \\ Universidad Autónoma de Aguascalientes, México
}

\begin{abstract}
The beginning of the 21st century in Mexico saw an increase in neoliberalism politics, including city planning strategies - at national and local levels. Leading sociologist and anthropologist Bartra says that Mexico now is the last wagon train of neoliberalism in Latin America. Cultural resources were also included in these politics with drastic changes -like a sudden increase of loss of built heritage. The positivist projects in the new urban designs - based on economics - may tear down some important historic buildings recently, ignoring also social aspects of the city. Besides this, the city now experiments with new urban centralities -basically corporate centralities - that become new economic poles, fragmenting the historic centre. Some of the macro urban planning projects in Mexico, like the Macro Plaza in Monterrey, the historic centre of Guadalajara and the urban projects of the main Zócalo in Mexico City, are examples of the great scale urban projects that change historic geographies. The new renovation project of Patria Square in Aguascalientes City focuses on the centenary year of the Mexican Revolution Convention of 1914 that took place in the Morelos Theatre. Now, one hundred years after this event, we face a new fragmentation of the old city infrastructure and architecture. The study of urban imaginaries, the macro urban renovations in the historic centre and the new urban centralities of the city could contribute to design good practices for the preservation and sustainability of built heritage. Also, the analysis of new urban corporate centralities versus the old centrality could determine if sustainable urban management can be achieved. The results of the paper show that tearing down buildings is not the best solution in historic preservation. Also there are some
\end{abstract}


other urban problems like the lack of water, subsidence and the need for new sustainable politics.

Keywords: historic preservation, sustainability, urban centralities.

\section{Introduction}

In recent years, remodelling historic places has become a common practice in Mexico. In Aguascalientes City, Patria Square is now being renovated. But city planners insist in changing historic geographies and residents are slowly losing their feeling of belonging to their local culture. The central square of Aguascalientes City is Patria Square and it has been renovated since the 16th century. But during the 20th century and the beginning of the 21 st century more frequent urban renovations occurred. These renovations make the places look different and the recent renovation of Patria Square makes it look more international because urban designers bring a lot of ideas from abroad specifically with the use of new materials. Then local cultures lose some identity with their own past. It is the use of positivist strategies in urban design projects that become the spaces look more contemporary. This paper explains benefits of using normative theories rather than positivist theories in urban design projects.

The analysis of new urban centralities could also help understand the loss of heritage. The new urban centralities in Aguascalientes are playing a different role than traditional urban centralities. As a result the users' preferences for visiting a historic centrality or a new centrality change dramatically because of consuming habits.

It is the use of new research methods in city planning -based on normative theories and qualitative research - that sustainability of historic places can effectively be achieved. Also the analysis factors like the problems of subsidence - produced by the lack of water - brings another problem to study: hundreds of houses are affected by land sinking to another level than normal in the historic centre and in the City of Aguascalientes.

\section{Renovation projects in the historic centre}

Some of the macro urban planning projects in Mexico have changed historic geographies. The Macro Plaza of Monterrey, the historic centre of Guadalajara, and the main Zócalo in Mexico City are examples of strong urban renovations. Patria Square in Aguascalientes is now being renovated too (fig. 1), following the example of some other Mexican cities that make projects to improve preservation of existing historic structures, although the goals of city planners are in a disagreement sometimes. At times city administrators prefer to tear down buildings to make open plazas rather than the preservation of historic buildings. The historic centre provides a sense of identity of residents because it is associated with the concept of community. But since the historic centre of Aguascalientes is slowly being torn down residents lose their feeling of belonging to the local culture. Tyler [1] says that with the loss of downtown comes the loss of the community's center. To borrow Gertrude Stein's words 
describing Oakland, California, "There is no there there." Also, there is a loss of the inherent historic character of the older historic centre when it is torn down. In addition, they are building important amounts of contemporary architecture in the centre of Aguascalientes.

During the 20th century, different renovations have occurred in Patria Square. In the year of 1949 a semi-circular theatre was built in the middle of the big square. The head of the Constructions Department of the City Hall: Roberto Álvarez Espinosa mentioned that the new theatre had a pure Versailles style. Also a brand new fountain honouring $\mathrm{M}$. Ponce was incorporated to the old column -built by Manuel Tolsá at the beginning of the 19th century - situated in the centre of the square. In 1967 the pavement in Patria Square was renovated and some of the monuments were moved to Alameda Ave. in the same city. The Architects Association of Aguascalientes then helped the City Hall administrators with project design ideas. In 1985 an urban renovation of Patria Square took place again, moving the old streetlights to the República Square in front of the Morelos Theatre, and aligning them with the large column

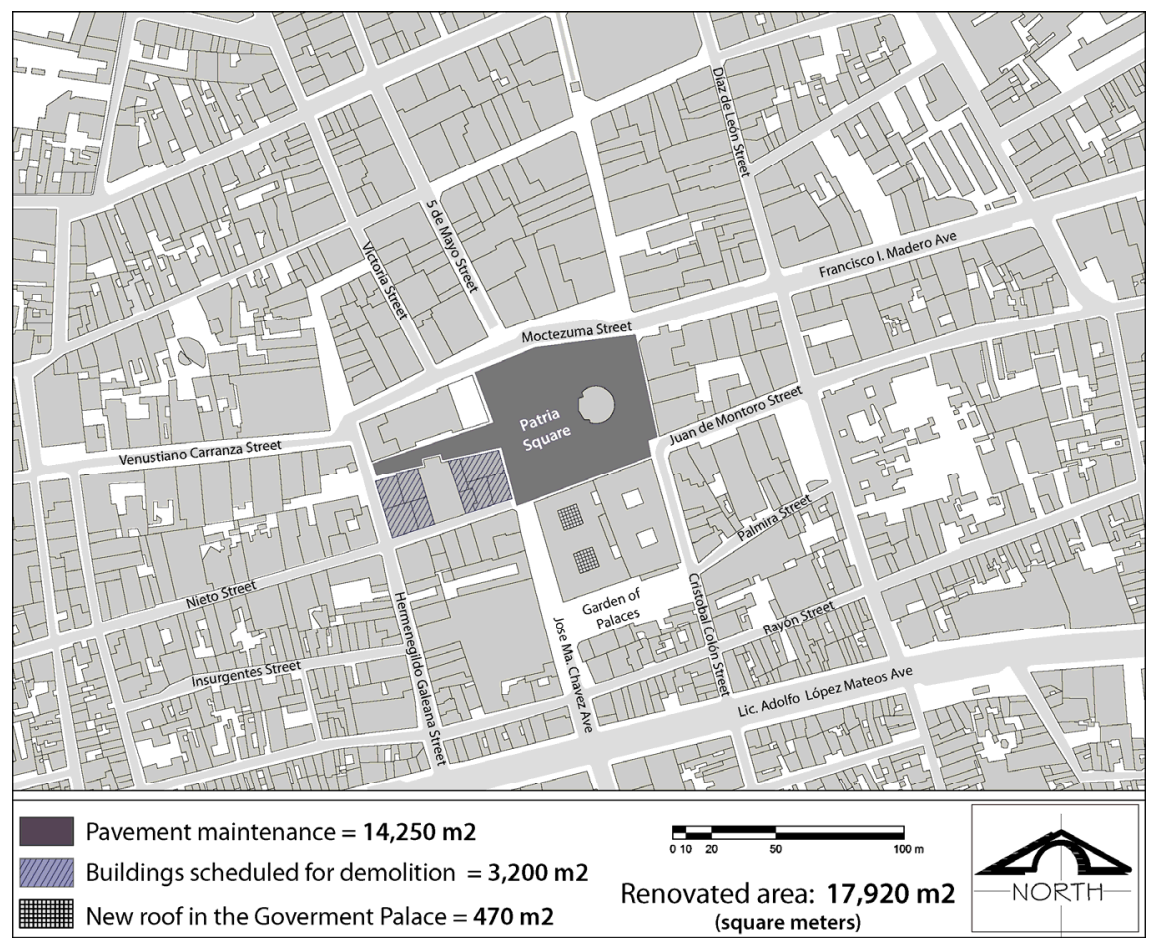

Figure 1: Patria Square is being remodelled now, including pavement maintenance. Also some buildings are scheduled for demolition and new roofs will be placed on the Government Palace. [Drawing: A. Acosta and G. Guillén, 2014.] 
of Patria Square. Also the República Square became a pedestrian precinct. At the top of the column the city administrators put an eagle sculpture symbolizing the old republican eagle of Mexico. Jesús F. Contreras made this sculpture.

The renovation project of Patria Square includes $14,250 \mathrm{~m}^{2}$ pavement maintenance, 3,200 $\mathrm{m}^{2}$ of buildings scheduled for demolition (fig. 2), and $470 \mathrm{~m}^{2}$ of two contemporary roofs that will be placed covering the main patios of the Government Palace (fig. 3). The total renovated area is $17,920 \mathrm{~m}^{2}$.

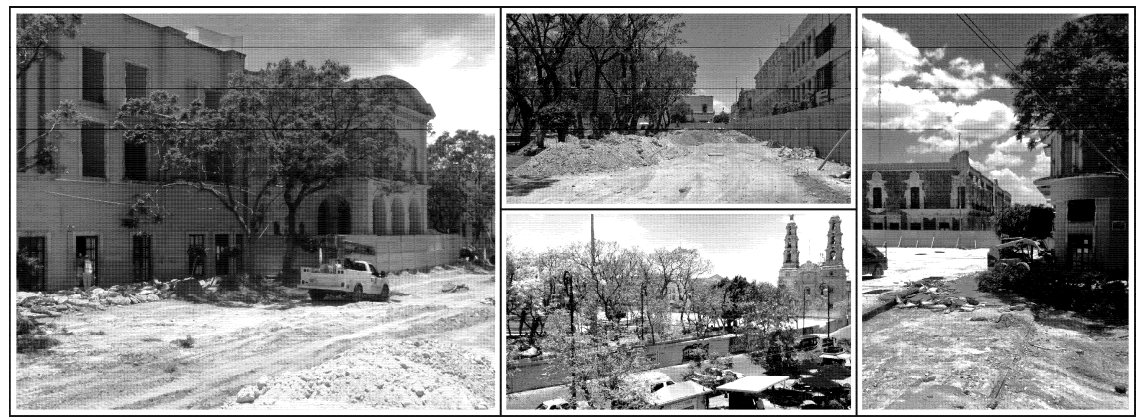

Figure 2: Buildings scheduled for demolition beside the Morelos Theatre, and pavement maintenance in the República Plaza and in Patria Square in Aguascalientes. [Photos: M. Martínez, May $31^{\text {st }} 2014$.]
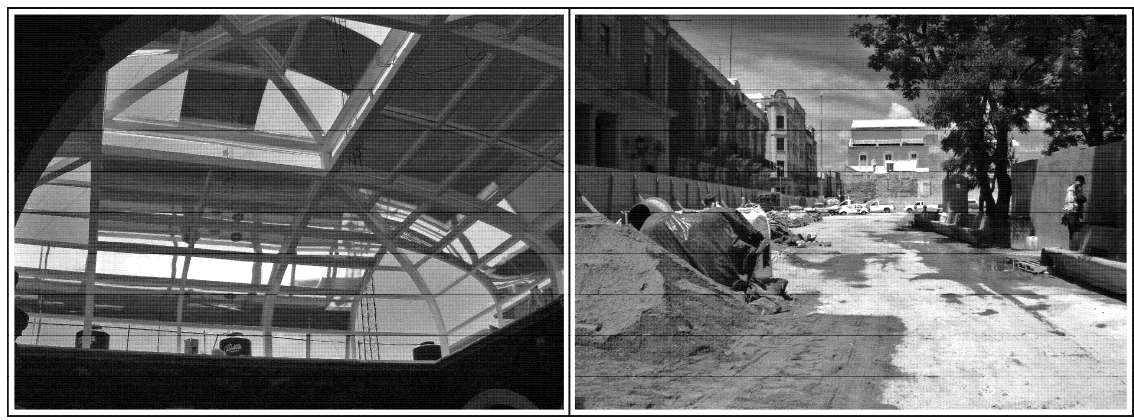

Figure 3: Installing brand new roofs with a contemporary design to cover the main patios of the historic Government Palace. [Photos: T. J. Pedroza, July 31st 2014].

The Government Palace of Aguascalientes, the main cathedral and Patria Square are located in the historic centre. The square area of $10,615 \mathrm{~m}^{2}$ makes it the biggest square of the city. Also it is the oldest one. The Morelos Theatre was built in 1882-1885 next to the cathedral. The architect José Noriega built it. But during the Mexican Revolution it took place in this theatre the National Revolution Convention in 1914. Nowadays, the renovation project of Patria Square in Aguascalientes focuses on the centenary year of the Revolution 
Convention of 1914. The urban project included a new arcade close to the Cathedral, based on a reinterpretation of two historic lithographs made by Egerton in 1840 and Nebel in 1830 (fig. 4). They are building this new arcade because there was an old market in that corner a long time ago, which was torn down.

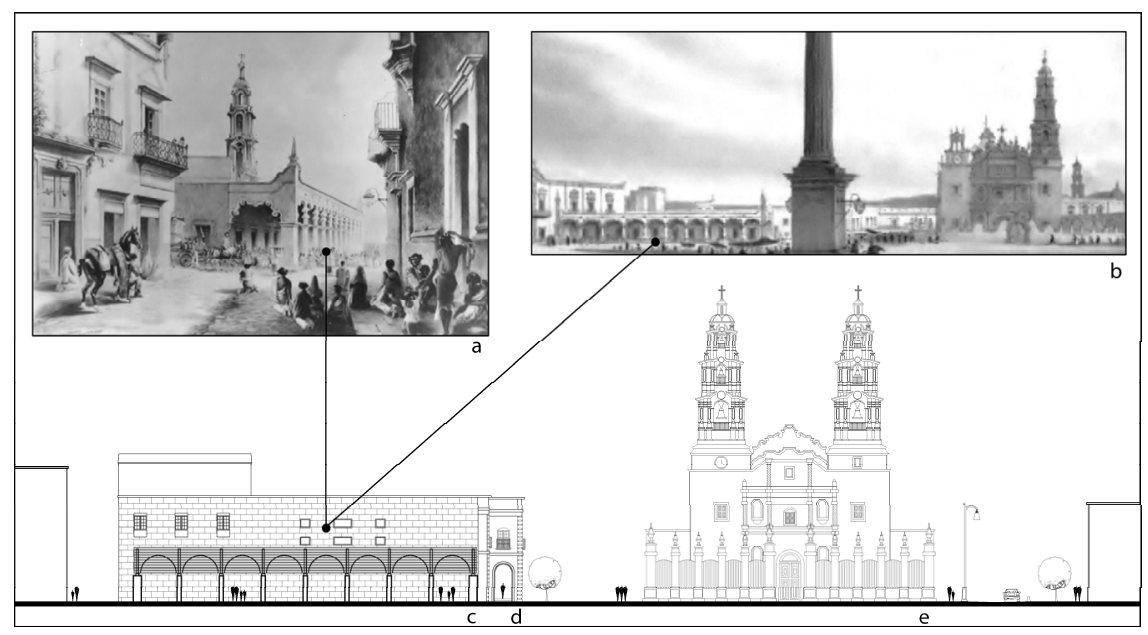

Figure 4: The use of historic images (lithographs made by: (a) Egerton, 1840, (b) Nebel, 1830) to re-build a contemporary arcade (c) was a recent idea in the renovation project of Patria Square. But with no covered walk, neither with a line of arches on one side -like it used to be in the 19th century. Behind this new arcade there is the Morelos Theatre (d). On the right there is the Cathedral (e) [Drawing: A. Acosta and G. Guillén, 2014].

The city planners sometimes use positivist strategies in urban design projects in the renovation of the historic centre. These projects are based on economics ignoring social aspects of the city. But the use of a normative theory could offer better results in design areas. Groat and Wang [2] mention normative theory is largely what motivates actions taken in design practice. Gary T. Moore, Emeritus Professor of Environment-Behaviour Studies at the University of Sydney, has proposed that positive theories are testable according to the laws of empirical reality, while normative theories (for instance, those related to design practice) are testable only by measures of professional acceptance, or longevity. In short, normative theory is often not as conducive to rigorous testing as positive theory is. Another way to look at it is this: Because normative theory is demonstrated by conventional practices that have withstood the test of time, it is arguable that any normative theory has already been tested - repeatedly, and every day, in the field. But the experiences of renovating projects in the historic centre of Monterrey and also the renovation of the historic centre of Guadalajara have received very strong critical opinions against demolition of buildings to benefit 
open spaces and plazas. Advice from professionals should be considered to make a decision in design projects. Also qualitative research should be applied in historic centre revitalization before the renovating works start.

\section{New centralities versus a traditional centrality}

Nowadays a diversity of urban centralities shows up in the city of Aguascalientes and in some other cities in Mexico. These new centralities -basically corporate make more complex the interconnections inside the city and with other cities surrounding Aguascalientes like Zacatecas, San Luis Potosí, León and Guadalajara. But it is possible to identify a transition between the activities of the visitors of the traditional place to the activities of the visitors in the new centralities. Since consuming has become more important nowadays the new centralities are ideal for this purpose. Even though residents like the new shopping malls the visitors still prefer historic places. A visitor mentions: 'if you travel from far away it is better to get to know historic places and eat regional food'.

The new urban centralities in the city are being built in strategic places based on market research, surveys and questionnaires. Nevertheless the historic centre is a static place and the oldest urban centrality in the main Mexican cities.

Also there are modern industries situated in southern Aguascalientes, which is led by the private sector. The biggest NISSAN factory complex of Latin America is located there producing an industrial centrality that brings services and interconnections between the factory and the city. Also proximity to the international airport and railroad lines were needed for the correct functioning of this complex. So the periphery of the city has new centralities surrounding the historic centre (fig. 5).

The oldest centrality is the Historic Centre (fig. 5(a)). It was founded in the 16th century and later settlements surrounded it through the time. San Ignacio factory settled down in western Aguascalientes in 1856 (fig 5(b)). This French factory included housing facilities for workers and the main building followed an industrial colony design from Europe. The foundation of this factory was supposed to be an industrial pole in Aguascalientes City. But it failed and the factory was abandoned at the beginning of the 20th century. World famous Guggenheim family decided to build a steel melting company (fig 5(c)) also in western Aguascalientes. It was a big factory with almost 4000 workers at the end of the 19th century. But it closed at the beginning of the 20th century too. This factory used to be connected to the city with trams. An important centrality of the city is the Railway complex (fig 5(d)). It brought technology and communication solutions to the city. Even though part of the complex was abandoned at the end of the 20th century new preservation projects are in progress now. New centralities appeared in the city of Aguascalientes in the second half of the 20th century. The Dorado mall (fig. 5(e)), Las Américas corporate buildings (fig. 5(f)) and Villasunción mall (fig. 5(g)) competed as new corporate centralities. Altaria mall (fig. 5(h)) at the beginning of the 21 st century became a strong centrality in Northern Aguascalientes. But it also became a 


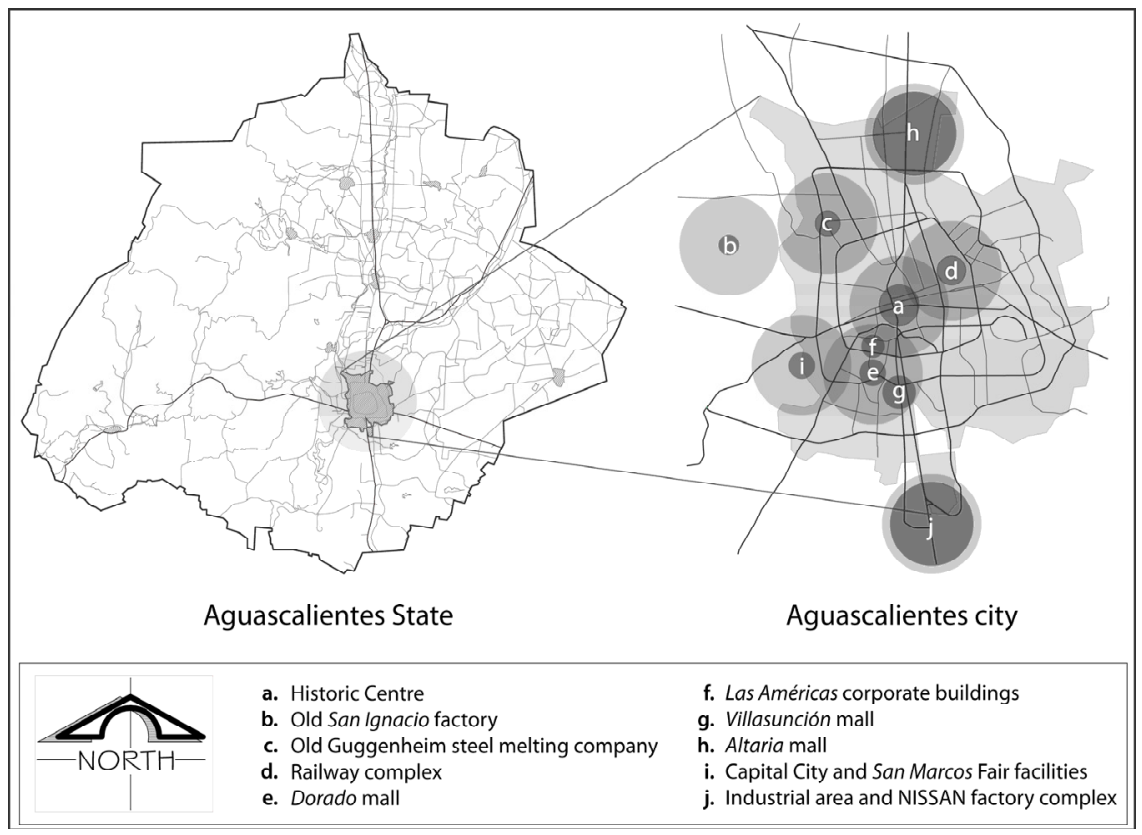

Figure 5: The main urban and economic centrality of Aguascalientes State is the capital: Aguascalientes City. Also this city has several urban and economic centralities. [Drawing: A. Acosta and G. Guillén, 2014.]

regional centrality. People from the State of Zacatecas and from the State of San Luis Potosí often come to Aguascalientes to consume in this mall. Capital City place and San Marcos Fair facilities have started recently as a temporary centrality (fig. 5(i)). This happened because the San Marcos National Fair activities take place once a year in the city. During 3 weeks of April and May almost 7 million people come to San Marcos Fair festivities and fair facilities each year. But the facilities become useless for the rest of the year. The newest important centrality of Aguascalientes is the NISSAN factory complex built in Southern Aguascalientes. This complex includes the biggest NISSAN factory complex of Latin America (fig. 5(j)). This centrality is situated close to Terán International Airport improving the most important industrial area of the city with new city infrastructure.

\section{Conclusions}

Knocking down buildings in the historic centre of Aguascalientes is tearing historic preservation apart. Urban planning in Mexico needs to include the citizens' opinions on possible urban changes to historic places. If society is integrated with their opinions about changes in historic places city planning could become more efficient. The use of questionnaires could become a useful researching tool to interpret opinions about remodelling projects. Although in 
Mexico we are not very used to ask people's points of views in historic centres planning. By observing the life of our own public spaces we can realize of what really happens. Life in historic centres has the immediacy of walking through the streets too (fig. 6). So open-ended questionnaires applied to street pedestrians can improve qualitative research in historic centre revitalization. Aguascalientes City has one million people living in the main urban area. But there is less than 5,300 people living in the historic centre. In fact people, in general, do not want to live in the historic centre because there is a lack of garages, it is away from the main shopping malls and building restoration is expensive.
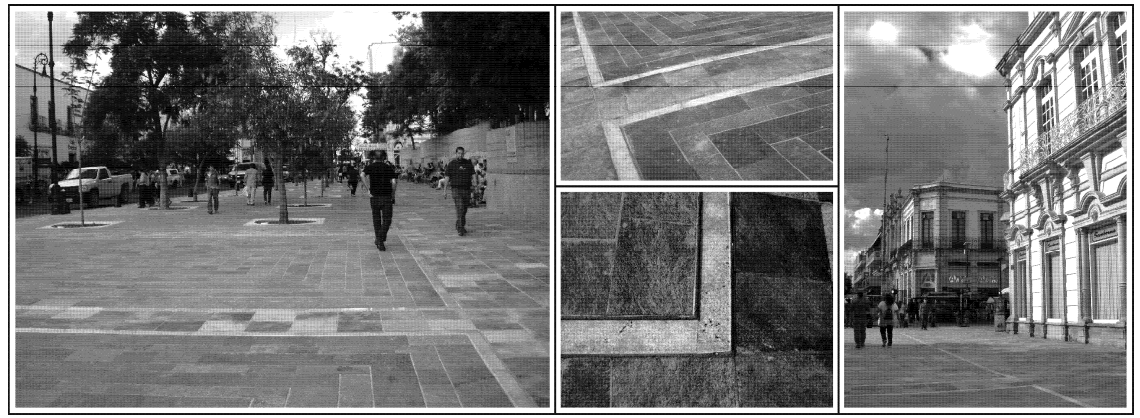

Figure 6: Patria Square Pavement maintenance. Life in historic centres has the immediacy of walking through the streets too. [Photos: T. J. Pedroza, August $4^{\text {st }}$ 2014.]

This research of the historic centre of Aguascalientes can be used as an explanatory example highlighting renovation principles in Mexican cities. An important conclusion in this paper is that city planners should insist on the recapture of the reality of things built and not in just making new sceneries.

Armstrong and Kapp [3] say that razing old buildings and replacing them with new construction is often detrimental to the historic continuity of the city and wastes valuable non-renewable energy and material resources. Recycling and re-purposing of old buildings, however, conserves embodied energy, preserves the historic and aesthetic character of existing buildings and neighbourhoods, and enhances the sense of "place" in communities by maintaining continuity with the past.

There is no physical encounter with the past by tearing down buildings. de Groot [4] indicates that museums and heritage projects have become increasingly important to a political agenda of lifelong learning, diversity and education. So city administrators should pay special interest when designing macro urban projects for historic places.

Nostalgia in historic preservation is a complex phenomenon. In addition some schools of historic preservation in Mexico are now including more research projects in history studies. de Groot [4] also argues that often it seems that historians wish to mark history out, to control and boundarise it; but it is in the transformations and transgressions of the historical that culture's desires, 

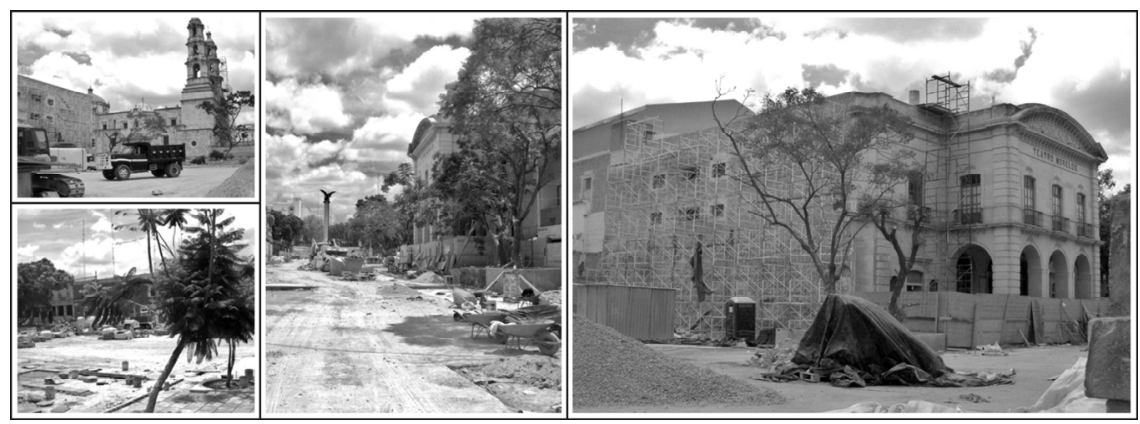

Figure 7: The macro urban project in Aguascalientes included pavement renovation and demolition of buildings. But there is no physical encounter with the past by tearing down buildings. [Photos: T. J. Pedroza, August 30th 2014.]

innermost workings, and underlying assumptions might be seen. Contemporary renovation of historic urban spaces still needs more analysis. Brom [5] says history is the result of decisions taken by the government too. But there are also some scientists in Mexico who want to help with good researches in urban projects now.

Different economic centralities in the city have produced severe problems in the historic centrality like: pollution, excessive mobility, tearing down buildings and loss of heritage. Nowadays there are two economic poles in the city produced by the most recent centralities: Altaria Mall and NISSAN factory complex (fig. 5), producing also urban changes inside the historic centrality.

New centralities in Aguascalientes have caused a problem of lack of water too. This is a problem that needs urgent attention in historic sustainability. The city has a domestic consumption of 186.40 liters/person/day, below the national average of 216.60.The lowering of water tables is accelerated to a speed of 2 meters deep annual average. Rainfall in the region is not sufficient to produce water table recovery; this turns into an uncontrolled situation. Sustainable development is directly linked to this process, which means, if there is not adequate water recharges it puts in danger ecosystems and life forms, including future generations. It is necessary to have less impermeable systems in city streets to recharge groundwater, improving natural recovery cycles. The recharge of water tables also depends on the rainy seasons. In late 2009 and early 2010 there were good harvests and decreased the drought [6]. Nowadays, the subsidence in Aguascalientes City has become a problem -because of the lowering of water tables - and hundreds of houses are becoming useless. Several areas of land are now sinking to another level than normal in the urban areas. 


\section{References}

[1] Tyler, N. Historic Preservation. An introduction to its history, principles, and practice, Norton: New York, p. 120, 2000.

[2] Groat, L. \& Wang, D. Architectural Research Methods, Wiley \& Sons, Inc.: United States of America and Canada, p. 78, 2002.

[3] Armstrong, P. J. \& Kapp, P.H., Post-industrial redevelopment and the mega-region: new strategies for the sustainable city of the $21^{\text {st }}$ century. The Sustainable City VII, Volume II, eds. M. Pacetti, G. Passerini, C. A. Brebbia \& G. Latini, WIT Press: Great Britain, p. 888, 2012.

[4] de Groot, J., Consuming history, historians and heritage in contemporary popular culture, Routledge: USA and Canada, pp. 236-250, 2009.

[5] Brom, J. Comprehending history, Grijalvo: Mexico, p. 131, 2014.

[6] Acosta, A. \& Parga, J.C., Cultural resources and sustainability: improving city planning and urban preservation in a Mexican city. The Sustainable City VII, Volume II, eds. M. Pacetti, G. Passerini, C. A. Brebbia \& G. Latini, WIT Press: Great Britain, p. 895, 2012. 